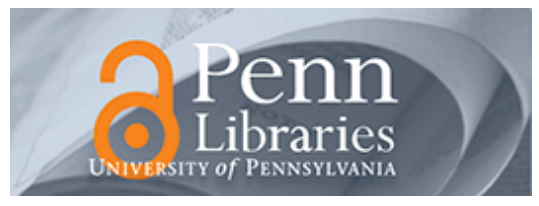

University of Pennsylvania

ScholarlyCommons

Statistics Papers

Wharton Faculty Research

$11-2010$

\title{
Gaming Performance Fees by Portfolio Managers
}

Dean P. Foster

University of Pennsylvania

H. Peyton Young

Follow this and additional works at: https://repository.upenn.edu/statistics_papers

Part of the Statistics and Probability Commons

\section{Recommended Citation}

Foster, D. P., \& Young, H. (2010). Gaming Performance Fees by Portfolio Managers. The Quarterly Journal of Economics, 125 (4), 1435-1458. http://dx.doi.org/10.1162/qjec.2010.125.4.1435

This paper is posted at ScholarlyCommons. https://repository.upenn.edu/statistics_papers/561

For more information, please contact repository@pobox.upenn.edu. 


\title{
Gaming Performance Fees by Portfolio Managers
}

\author{
Abstract \\ Any compensation mechanism that is intended to reward superior investment performance can be \\ gamed by managers who have no superior information or predictive ability; moreover they can capture a \\ sizable amount of the fees intended for the superior managers. We derive precise bounds on the size of \\ this coat-tail effect and show that it remains substantial even when payments are postponed, bonuses \\ are subject to clawback provisions, or outright penalties are imposed for poor performance. This \\ impossibility result stands in contrast to performance measures, some of which are invulnerable to \\ manipulation. \\ Disciplines \\ Statistics and Probability
}




\title{
Gaming Performance Fees by Portfolio Managers
}

\author{
Dean P. Foster* and H. Peyton Young**
}

This version: March 19, 2009

${ }^{*}$ Department of Statistics, Wharton School, University of Pennsylvania

**Department of Economics, University of Oxford

Acknowledgements: We are indebted to Pete Kyle, Andrew Lo, Andrew Patton, Tarun Ramadorai, Krishna Ramaswamy, Neil Shephard, and Robert Stine for helpful suggestions.

An earlier and more informal version of this paper was entitled "The Hedge Fund Game: Incentives, Excess Returns, and Performance Mimics," Wharton Financial Institutions Center Working Paper 07-42, University of Pennsylvania, 2007. 


\begin{abstract}
Any compensation mechanism that is intended to reward superior investment performance can be gamed by managers who have no superior information or predictive ability; moreover they can capture a sizable amount of the fees intended for the superior managers. We derive precise bounds on the size of this coat-tail effect and show that it remains substantial even when payments are postponed, bonuses are subject to clawback provisions, or outright penalties are imposed for poor performance. This impossibility result stands in contrast to performance measures, some of which are invulnerable to manipulation.
\end{abstract}




\section{Background}

It is well-known that when fund managers have unconstrained access to derivatives, they can manipulate the returns distribution in order to enhance their performance under standard performance measures, such as the Sharpe ratio, the appraisal ratio, and Jensen's alpha (Ferson and Siegel, 2001; Lhabitant, 2000; Goetzman, Ingersoll, Spiegel and Welch, 2007; Guasoni, Huberman, and Wang, 2007). It is also known that performance measures can be constructed that are immune to manipulation. These take the form of a constant relative risk aversion utility function averaged over the returns history. Subject to certain regularity conditions, these are in fact the only performance measures that are manipulation-proof (Goetzmann et al., 2007).

In this paper we show that a similar "possibility" theorem does not hold for compensation mechanisms. Under any method of structuring incentive payments for superior performance, managers with no superior information or skill can capture a portion of the fees intended to reward those managers who do have such information or skill. In effect, managers who have no ability can ride on the coat-tails of managers who do. This result holds not only for the two-part payment schemes that are common in the hedge fund industry, but also for delayed bonus payments, high water marks, contracts in which bonuses in good years are offset by "maluses" in bad years, and other types of payment schemes that are designed to deter manipulation. 
The idea that compensation mechanisms may induce managers to engage in some forms of manipulation has been discussed in the prior literature. In particular, the convexity of the usual two-part fee structure, and the asymmetric treatment of gains and losses, create incentives to take on increased risk without necessarily providing additional returns to investors. (See among others Starks (1987), Ackermann, MacEnally, and Ravenscraft (1999), Carpenter (2000), Lo (2001), and Hodder and Jackwerth (2007)). The contribution of the present paper is to show that essentially any compensation mechanism is vulnerable to manipulation, that the extent of the manipulation can be estimated in a precise way, and that the amounts that can be earned by manipulation are potentially large even when the mechanism is designed to thwart manipulative behavior.

The strategies that we shall use to derive this result consist of holding a benchmark portfolio and writing options on it (buy-write strategies). Lo (2001) was one of the first to demonstrate how such an approach can be used to deliver apparent 'excess' returns without producing any value-added for investors. ${ }^{1}$ Similar strategies arise in the context of maximizing appraisal ratios (Guasoni, Huberman, and Wang, 2007). Thus the use of buy-write strategies to manipulate performance is well-known. Here we show how this same class of strategies can be used to derive a precise mathematical statement about how much fee capture is theoretically possible and that it is virtually impossible to prevent it.

Before turning to these results, however, we need to clarify why fees can be gamed when Goetzmann et al. (2007) have shown that there are perfectly

\footnotetext{
${ }^{1}$ Lo examined the case in which a manager takes short positions in S\&P 500 put options that mature in 1-3 months and are about 7\% out-of-the-money, and estimated the excess returns that would have been generated relative to the market in the 1990s.
} 
reasonable performance measures that cannot be gamed. For example, why would it not suffice to pay the manager according to a linear increasing function of a manipulation-proof measure? It turns out that this does not work because invulnerability to manipulation is more demanding when applied to compensation instead of to performance. The difficulty is that a compensation mechanism must screen out unskilled managers who create no value-added to investors, while offering positive incentives to managers who do create valueadded in the form of excess returns. It turns out that this is impossible: either the mechanism allows some managers to be paid even though they offer no excess returns in expectation, or the mechanism levies penalties that keep out both the skilled and unskilled managers. Moreover, the inability to screen out the unskilled from the skilled is not minor: if skilled managers have positive expected earnings, then unskilled managers can capture a sizable amount of the earnings intended for the skilled.

Our method for proving these results uses a combination of game theory, probability theory, and elementary options pricing. The game theoretic component is novel and relies on a variant of a concept known as strategy-stealing (Gale, 1974). This is a device for analyzing games that are so complex that the explicit construction of equilibrium strategies is difficult or impossible; nevertheless it is sometimes possible to compare the players' payoffs in equilibrium without knowing what the equilibrium is.

The general idea runs as follows: suppose that one player in a game (say $i$ ) has a certain strategy $s_{i}$ that results in payoff $\alpha_{i}$. Then another player (say $j$ ) can copy i's strategy and get a payoff at least as high as $\alpha_{i}$. Gale originally applied this 
idea to a board game called Chomp, which is similar to Nim. In particular, he showed that the first mover must have a winning strategy even though he (Gale) could not construct it: for if the second mover had a winning strategy, the first mover could 'steal' it and win instead.

We shall show that a version of this argument holds in financial markets with options trading. Namely, a manager with no private information or special skills can mimic the returns being generated by another (more skilled) manager for an extended period of time without knowing how the skilled manager is actually producing these returns. ${ }^{2}$ Using a martingale construction, we show how to compute the probability with which the unskilled manager can mimic the skilled one over any specified length of time, and we establish a lower bound on how much he will earn in the process. A key feature of the argument is that the unskilled manager does not have to know anything about the actual investment strategy being employed by the skilled manager. Nevertheless, the unskilled manager can exactly reproduce the returns sequence being generated by the skilled manager with high probability, though this may entail losing all the investors' money with small probability. In the meantime he earns fees and attracts customers just as if he were skilled.

\footnotetext{
${ }^{2}$ It should be emphasized that mimicry is not the same as cloning or replication (Kat and Palaro, 2005; Hasanhodzic and Lo, 2007). These strategies seek to reproduce the statistical properties of a given fund or class of funds, whereas mimicry seeks to fool investors into thinking that returns are being generated by one type of distribution when in fact they are being generated by a different (and less desirable) distribution.
} 


\section{Paying for performance}

Consider a benchmark portfolio that generates a sequence of returns in each of $T$ periods. Throughout we shall assume that returns are reported at discrete intervals, say at the end of each month or each quarter. Let $r_{f t}$ be the risk-free rate in period $t$ and let $X_{t}$ be the total return of the benchmark portfolio in period $t$, where $X_{t}$ is a nonnegative random variable whose distribution may depend on the prior realizations $x_{1}, x_{2}, \ldots, x_{t-1}$. A fund that has initial value $X_{0}=1$ and is passively invested in the benchmark will therefore have value

$\prod_{1 \leq t \leq T} X_{t}$ by the end of the $T^{\text {th }}$ period. If the benchmark asset is risk-free then $X_{t}=1+r_{f t}$. Alternatively, $X_{t}$ may represent the return on a broad market index such as the S\&P 500, in which case it is stochastic, though we do not assume stationarity.

Portfolio managers are paid according to the returns they generate compared with the returns from a suitably chosen benchmark portfolio. Let the random variable $Y_{t} \geq 0$ denote the period-by-period returns generated by a particular managed portfolio, $1 \leq t \leq T$. It will be mathematically convenient to express the returns of the managed portfolio as a multiple of the returns generated by the benchmark portfolio. Specifically, let us assume that $X_{t}>0$ in each period $t$, and define the random variable $M_{t} \geq 0$ such that

$$
Y_{t}=M_{t} X_{t}
$$


We can express the excess returns relative to the benchmark as follows:

$$
Y_{t}-\left(1+r_{f t}\right)=M_{t}\left(X_{t}-1-r_{f t}\right)+\left(M_{t}-1\right)\left(1+r_{f t}\right) .
$$

If $M_{t}$ and $X_{t}$ are independent, we can interpret the second term on the righthand side of (2) as the alpha generated by the manager:

$$
A_{t}=\left(M_{t}-1\right)\left(1+r_{f t}\right) .
$$

A compensation contract up to time $T$ is a function $\phi$ such that, for each period $1 \leq t \leq T$, and every pair of realized sequences $\vec{x}=\left(x_{1}, x_{2}, \ldots, x_{T}\right), \vec{m}=\left(m_{1}, m_{2}, \ldots, m_{T}\right)$, $\phi_{t}(\vec{m}, \vec{x})$ is the payment to the manager in period t per dollar in the fund at the start of the period, where $\phi_{t}(\vec{m}, \vec{x})$ depends only on the prior realizations $x_{1}, \ldots, x_{t-1}$ and $m_{1}, \ldots, m_{t-1}$. In view of (3), it is natural to assume that $\phi_{t}(\vec{m}, \vec{x})$ is monotone nondecreasing in $m_{s}$ for all $s \leq t$, although we shall not actually need this condition for our results.

This formulation is very general, and includes standard incentive schemes as well as commonly proposed alternatives. For example, the payment in period $t$ can arise from postponed bonuses that were earned for good performance in prior periods. The set-up also allows for clawback provisions: bonuses that were "earned" in prior periods can be offset by maluses in later periods if subsequent performance is poor. These and many other variations are encompassed in the assumption that the payment in period $t, \phi_{t}(\vec{m}, \vec{x})$, can depend on the entire sequence of returns that has gone before. 
Let us consider some simple examples. Suppose that the manager charges a $2 \%$ management fee at the start of each period and a $20 \%$ performance bonus on the return generated during the period above the risk-free rate. This can be expressed as

$$
\phi_{t}(\vec{m}, \vec{x})=.02+.2\left(m_{t} x_{t}-1-r_{f t}\right)_{+} .
$$

Alternatively, suppose that the $20 \%$ performance bonus is only paid at the end of the fund's lifetime, say after $T$ years, when the proceeds are distributed among the original investors. Assume for simplicity that the fund is closed to new investments and withdrawals until then, and let the initial size of the fund be 1 . For each year $t<T$ we have $\phi_{t}(\vec{m}, \vec{x})=.02$ due to the management fee. At the end of year $T$ the performance bonus will be $20 \%$ of the cumulative excess return relative to the risk-free rate over the life of the fund, that is, $.2\left[\prod_{1 \leq t \leq T} m_{t} x_{t}-\prod_{1 \leq t \leq T}\left(1+r_{f t}\right)\right]_{+}$. The management fee in year $T$ will be .02 times the size

of the fund at the start of the year, which is $(.98)^{T-1} \prod_{1 \leq t \leq T-1} m_{t} x_{t}$. By definition, $\phi_{T}(\vec{m}, \vec{x})$ is the total fee in year $T$ per dollar in the fund at the start of the year, hence

$$
\phi_{T}(\vec{m}, \vec{x})=.02+\frac{.2\left[\prod_{1 \leq t \leq T} m_{t} x_{t}-\prod_{1 \leq t \leq T}\left(1+r_{f t}\right)\right]_{+}}{(.98)^{T-1} \prod_{1 \leq t \leq T-1} m_{t} x_{t}} .
$$

\section{Mimicry}

We shall say that a manager has superior skill if, in expectation, he delivers excess returns relative to the benchmark portfolio, either through private information, superior predictive powers, or access to payoffs outside the benchmark payoff 
space. A manager has no skill if he cannot deliver excess returns relative to the benchmark. Assuming that the benchmark portfolio is widely available (e.g., it represents a broad market index and derivatives on the index), investors should not be willing to pay for managers who have no skill. We claim, however, that such payments are unavoidable: any scheme that pays managers with superior skill can be gamed by managers with no skill to earn substantial payments also.

We shall first show this in the case where payments are nonnegative, that is, $\phi_{t}(\vec{m}, \vec{x}) \geq 0$ for all $t, \vec{m}, \vec{x}$. In a subsequent section we shall show that the same holds when monetary penalties are imposed for underperformance, that is, $\phi_{t}(\vec{m}, \vec{x})<0$ for some realizations. Note that the latter condition is much stronger than saying that managers' bonuses are subject to clawback provisions. Rather, it says that there are circumstances under which the manager must pay for underperformance out of his own private funds. (By contrast, clawback provisions can reduce prior bonuses but they do not normally lead to net assessments against the manager's personal assets.)

Fix a non-negative compensation contract $\phi$ that is benchmarked against a portfolio generating a stochastic sequence of returns $\vec{X}=\left(X_{1}, X_{2}, \ldots, X_{T}\right)$. Let $i$ be a manager whose portfolio generates returns $Y_{t}^{i}=M_{t}^{i} X_{t}$. We shall say that the manager generates excess returns in period $t$ if $M_{t}^{i}$ and $X_{t}$ are independent and $E\left[M_{t}^{i}\right] \geq 1$ for every $t$. He consistently generates excess returns if $m_{t}^{i} \geq 1$ for all realizations of $M_{t}^{i} .^{3}$

\footnotetext{
${ }^{3}$ The independence assumption is mainly for technical convenience and our subsequent results do not actually depend on it. In any event it is the natural case to consider given that investors want excess returns that are orthogonal to the benchmark portfolio; returns that are correlated can be achieved simply by leveraging the benchmark.
} 
Given a realization of returns on the benchmark portfolio, $\vec{x}=\left(x_{1}, x_{2}, \ldots, x_{T}\right)$, define the cut of manager $i$ in period $t$ to be his expected earnings per dollar in the fund at the end of the period. ${ }^{4}$ This is computed as follows: for each realization $\vec{m}=\left(m_{1}, m_{2}, \ldots, m_{T}\right), \phi_{t}(\vec{m}, \vec{x})$ is the manager's fee per dollar in the fund at the start of period $t$. Since the fund grows by the factor $m_{t} x_{t}$ during the period, the manager's fee per dollar at the end of the period is $\phi_{t}(\vec{m}, \vec{x}) / m_{t} x_{t}$. The cut is the expectation of this quantity conditional on $\vec{x}$, namely,

$$
c_{t}\left(\vec{M}^{i} \mid \vec{x}\right)=E\left[\frac{\phi_{t}\left(\vec{M}^{i} \mid \vec{x}\right)}{M_{t}^{i} X_{t}}\right] .
$$

To illustrate, suppose that $\phi$ consists solely of a $2 \%$ management fee that is levied on the funds at the start of each period. Then the cut is $.02 E\left[1 / M_{t} X_{t}\right]$. If $\phi$ consists solely of a bonus payment equal to $20 \%$ of the returns in excess of the risk-free rate, the cut is $.20 E\left[\left(M_{t} x_{t}-1-r_{f t}\right)_{+} / M_{t} x_{t}\right]$, and so forth.

Theorem 1. Fix a nonnegative compensation contract $\phi$ over $T$ periods that is benchmarked against a portfolio generating returns $\vec{X}=\left(X_{1}, X_{2}, \ldots, X_{T}\right)>\overrightarrow{0}$. Let $i$ be a skilled manager whose strategy $\vec{M}^{i} \geq \overrightarrow{1}$ consistently generates excess returns relative to $\vec{X}$. Then an unskilled mimic has a strategy $\vec{M}^{0}$ that generates expected fees at least equal to $c_{t}\left(\vec{M}^{i} \mid \vec{x}\right)\left(x_{1} x_{2} \cdots x_{t}\right)$ in every period $t$ and for every realization $\vec{x}$. Thus, in expectation, the mimic earns as high a percentage of the benchmark portfolio as the skilled manager earns of his portfolio.

\footnotetext{
${ }^{4}$ This terminology differs somewhat from our earlier paper (Foster and Young, 2007).
} 
Before turning to the proof, we note several key points. First, the mimic does not need to know how the target manager $i$ is generating the returns $Y_{t}^{i}=M_{t}^{i} X_{t}$, all he has to do is mimic the distribution of returns. Second, the proof will show that he does not need any special investment skill or access to assets outside the benchmark payoff space to achieve this; it suffices to use straightforward trading strategies in options written on the benchmark assets. Therefore he does not produce any real value-added for the investors, and his expected returns are no higher than the expected returns that would be generated by passively investing in the benchmark portfolio. Nevertheless, in expectation he can earn fees that are as high (as a percentage of funds under management) as does a skilled manager who generates high levels of alpha.

Third, since there is no restriction on which skilled manager the mimic may choose to target, it makes sense to choose one whose stellar performance garners particularly high fees. In fact, there is no need to target a manager who actually exists; it suffices to choose a pattern of returns that would be construed as stellar and would earn correspondingly high fees if such a manager did exist.

Fourth, the ability of the mimic to capture fees remains very strong even when fees are postponed, high water marks are imposed, and other features are introduced to try to limit the extent to which fees can be manipulated. Whatever these features are, they apply equally to the high ability managers and to the mimics: if the contract rewards the former (perhaps in some future period), then the mimic can capture a portion of that reward in the same period. 
Lastly, one might hope that these problems could be circumvented by levying outright penalties on underperformance, i.e., by requiring managers to post a bond that they forfeit under certain conditions. Indeed, this is one consequence of assessing fees according to manipulation-proof performance measures of the type proposed by Goetzmann et al. (2007). Unfortunately, this remedy does not work either, because penalties that are large enough to deter the mimics will keep all the skilled managers out of the market as well, as we show in section 7.

\section{Proof of theorem 1 .}

Let the benchmark portfolio consist of a weighted combination of stocks and a risk-free asset such as Treasury bills. To simplify the exposition we shall consider the two polar cases in which the portfolio is invested entirely in a broad market index, such as the S\&P 500, or is invested entirely in the risk-free asset. The extension to combinations of these portfolios is left to the reader. The key to the proof is the following result.

Lemma. Consider any target sequence of excess returns $\vec{m}=\left(m_{1}, \ldots, m_{T}\right) \geq(1,1, \ldots, 1)$. A mimic has a strategy $\vec{M}^{0}(\vec{m})$ that generates the returns sequence $\left(m_{1} x_{1}, \ldots, m_{T} x_{T}\right)$ with probability at least $1 / \prod_{1 \leq t \leq T} m_{t}$ for every realized sequence of returns $\vec{x}$ of the benchmark portfolio.

Assume for the moment that the Lemma has been established, and we shall show how it leads to the proof of theorem 1. Suppose that a skilled manager $i$ has a strategy $\vec{M}^{i}$ that consistently generates excess returns relative to $\vec{X}$. The mimic's strategy $\vec{M}^{0}$ is constructed as follows. First he chooses a target sequence 
of excess returns $\vec{m} \geq \overrightarrow{1}$ according to the same probability distribution that generates $\vec{M}^{i}$. (Notice that this does not require him to know how the excess returns are being generated; he merely has to know how they are distributed.) Then the mimic implements the strategy $\vec{M}^{0}(\vec{m})$ defined in the Lemma. Under this strategy, for every $\vec{x}$, the mimic earns $\phi_{t}(\vec{m}, \vec{x})$ per dollar in the fund at the start of the period with probability at least $1 / m_{1} m_{2} \cdots m_{t}$. By assumption $\phi$ is nonnegative. Therefore, irrespective of the other outcomes that may be generated by the mimic's strategy, for every $\vec{x}$ his expected fee in period $t$ must be at least

$$
\frac{\phi_{t}(\vec{m}, \vec{x})\left(m_{1} m_{2} \cdots m_{t-1}\right)\left(x_{1} x_{2} \cdots x_{t-1}\right)}{m_{1} m_{2} \cdots m_{t}}=\frac{\phi_{t}(\vec{m}, \vec{x})\left(x_{1} x_{2} \cdots x_{t}\right)}{m_{t} x_{t}} .
$$

Since $\vec{m}$ is chosen as a target under $\vec{M}^{0}$ with the same probability that it actually occurs under $\vec{M}^{i}$, it follows that the mimic's expected fee under $\vec{M}^{0}$ satisfies

$$
\forall \vec{x} \forall t \quad E_{\vec{M}^{0}}\left[\phi_{t}\left(\vec{M}^{0}, \vec{x}\right)\right] \geq E_{\vec{M}^{i}}\left[\frac{\phi_{t}\left(\vec{M}^{i}, \vec{x}\right)}{M_{t}^{i} x_{t}}\right]\left(x_{1} x_{2} \cdots x_{t}\right) .
$$

By definition the right-hand side of (8) is $c_{t}\left(\vec{M}^{i} \mid \vec{x}\right)\left(x_{1} x_{2} \cdots x_{t}\right)$. This completes the proof of theorem 1.

Proof of lemma. We will first treat the case where the benchmark portfolio consists of a risk-free asset such as Treasury bills yielding the risk-free rate $r_{f t}$ in period $t$. In this case $x_{t}=1$ for all $t$. Fix a target sequence of excess returns 
$\vec{m}=\left(m_{1}, \ldots, m_{T}\right) \geq(1,1, \ldots, 1)$. We need to show that the mimic has a strategy that delivers a total return $m_{t}\left(1+r_{f t}\right)$ with probability at least $1 / m_{t}$.

The first step is to choose a commonly traded stochastic asset, such as the S\&P 500, on which binary cash-or-nothing options can be written. We shall make the customary assumption that the price of the index, $P_{t}$, follows a continuous-time geometric Brownian motion of form

$$
d P_{t}=\mu P_{t} d t+\sigma P_{t} d W_{t}
$$

The prices are observed only at discrete intervals $t=1,2,3 \ldots$. Let the continuoustime risk-free rate in period $t$ be $\tilde{r}_{f t}$, so that $r_{f t}=e^{\tilde{r}_{t t}}-1$. We assume that the benchmark asset's returns are at least as high as the risk-free rate: $\tilde{r}_{f t} \leq \mu$.

Consider a given period $t$. At the start of the period the mimic invests everything in the risk-free asset yielding $r_{f t}$. At some randomly chosen time during the period, he writes (or shorts) a certain quantity $q$ of cash-or-nothing puts that expire before the end of the period. Assume that each option pays one dollar if exercised; otherwise it pays nothing. Let $\Delta$ be the time to expiration and let $s$ be the strike price divided by the current price; without loss of generality we may assume that the current price is 1 . Let $\Phi$ denote the cumulative normal distribution function. Then the option's present value is $e^{-\tilde{r}_{t} \Delta} v$ where

$$
v=\Phi\left[\left(\ln s-\tilde{r}_{f t} \Delta+\sigma^{2} \Delta / 2\right) / \sigma \sqrt{\Delta}\right] .
$$

The probability that the put will be exercised is 


$$
p=\Phi\left[\left(\ln s-\mu \Delta+\sigma^{2} \Delta / 2\right) / \sigma \sqrt{\Delta}\right]
$$

Assume that the fund currently has $w$ dollars. By selling $q$ options he collects an additional $v q$ dollars. By investing them all in the risk-free asset, he can cover up to $q$ options if they are exercised, where $e^{\tilde{r}_{f t} \Delta} w+v q=q$. Thus $q=w e^{\tilde{r}_{f t} \Delta} /(1-v)$. The mimic chooses the time to expiration $\Delta$ and the strike price $s$ so that $v$ satisfies $v=1-1 / m_{t} \cdot{ }^{5}$ With probability $p$ the options are exercised and the fund is entirely cleaned out (i.e., paid to the option-holders). With probability $1-p$ the options expire without being exercised, in which case the fund has grown by the factor $m_{t} e^{\tilde{r}_{f t} \Delta}$ over the time interval $\Delta$. The manager enters into this gamble only once per period, and the funds are invested in the risk-free asset during the remaining time, hence the total return during the period is $m_{t}\left(1+r_{f t}\right)$ with probability $1-p$ and zero with probability $p$.

We claim that $p \leq v$; indeed this follows immediately from (10) and (11) and the assumption that $\tilde{r}_{f t} \leq \mu$. Therefore, if the mimic had $w_{t-1}>0$ dollars in the fund at the start of period $t$, then by the end of the period he will have $m_{t}\left(1+r_{f t}\right) w_{t-1}$ dollars with probability at least $1 / m_{t}=1-v$ and zero dollars with probability at most $1-1 / m_{t}$. Therefore after $T$ periods, he will have generated the target sequence of excess returns $\left(m_{1}, \ldots, m_{T}\right)$ with probability at least $1 / \prod_{1 \leq t \leq T} m_{t}$, as asserted in the lemma.

\footnotetext{
${ }^{5}$ Note that the strike price need not be far out of the money if the time to expiration is short, hence the Black-Scholes formula can be assumed to hold with a high degree of accuracy.
} 
Next let us consider the case where the benchmark sequence $\vec{X}$ is generated by a market index (or more generally any stochastic asset on which options are traded). As before, we assume that the price per share of the asset is described by the stochastic process (9). In this case the mimic shorts a number of asset-ornothing options that pay out one share of the asset if the strike price is exceeded. (Asset-or-nothing options can be created from plain-vanilla European options and cash-or-nothing options.) As before, let $\Delta$ be the time to expiration and $\tilde{r}_{f t}$ the continuous-time risk-free rate. For simplicity we shall assume there no dividend. Let $s$ be the strike price divided by the current price. Then the present value of one asset-or-nothing put is (see for example Hull, 2009, section 24.7)

$$
v=\Phi\left[\left(\ln s-\tilde{r}_{f t} \Delta-\sigma^{2} \Delta / 2\right) / \sigma \sqrt{\Delta}\right] .
$$

The probability that the put is exercised is

$$
p=\Phi\left[\left(\ln s-\mu \Delta+\sigma^{2} \Delta / 2\right) / \sigma \sqrt{\Delta}\right] .
$$

As before we need to have $p \leq v$, which will be the case if $\mu-\tilde{r} \geq \sigma^{2}$. (If $\mu-\tilde{r}<\sigma^{2}$, the mimic shorts asset-or-nothing calls instead of asset-or-nothing puts.) The construction now parallels the previous case. At the start of the $t^{\text {th }}$ period the mimic invests everything in the benchmark asset. At some randomly chosen time during the period, he writes the maximum number of asset-ornothing options that he can cover, where the strike price and time to expiration are chosen so that the probability they are exercised is at most $1-1 / m_{t}$. Thus, with probability at least $1 / m_{t}$, this strategy increases the number of shares in the fund 
by the factor $m_{t}$. Hence, with probability at least $1 / m_{t}$, it delivers a total return equal to $m_{t}\left(P_{t} / P_{t-1}\right)=m_{t} X_{t}$.

Over the $T$ periods, the strategy therefore generates the return sequence $\left(m_{1} x_{1}, \ldots, m_{T} x_{T}\right)$ with probability at least $1 / \prod_{1 \leq t \leq T} m_{t}$ for every realization $\vec{x}$ of the benchmark portfolio. This concludes the proof of the lemma, and likewise the proof of theorem 1.

The probability bound in the Lemma is somewhat conservative; indeed slightly better results can be achieved by shorting puts that are far out-of-the-money (due to the smile effect). While the bound may not be best possible, however, it is easy to work with analytically and suffices to show how well mimics can do while providing no value-added to investors. To the extent that they can do better using refinements of this approach, our conclusions hold with even greater force.

\section{A numerical example}

To see how theorem 1 can be applied, let us run through an illustrative calculation. Suppose that a highly skilled manager has a strategy that delivers excess returns of $10 \%$ every year for ten years relative to a risk-free rate of $4 \%$. Thus the fund's annual return before fees is $(1.10)(1.04)=1.144$. Under a two and twenty contract the manager's annual fee will be $2 \%$ of the fund's value at the start of the year plus a $20 \%$ performance bonus at the end of the year. Altogether this comes to $3.57 \%$ of the fund's year-end value before fees, that is, $(.02+.20(.144-.04)) / 1.144 \approx 0.0357$. Thus the manager's cut is $3.57 \%$. Theorem 1 
says that a manager with no skill has a mimicking strategy that delivers the appearance of $10 \%$ excess returns and in expectation earns at least $3.57 \%$ per year of a fund invested solely in the risk-free asset compounding at $4 \%$ per annum. (In fact, this is an underestimate, because the management fee will be collected even in a year in which the fund loses all of its money.)

Theorem 1 implies that any attempt to redesign the fees in order to deter the mimics will have only a limited effect, because they can ride on the coat-tails of the fees earned by the skilled managers. Suppose, for example, that the manager's performance bonus is only earned at the end of ten years, at which point the fund closes and the investors are paid back. (Assume for the moment that the fund takes in no new money over its lifetime; the alternative case will be considered in section 8.) Consider a skilled manager who generates $10 \%$ returns in excess of the risk-free rate $(4 \%)$. In each year $t, 1 \leq t<10$, his cut will be $C_{t}=.02 / 1.144 \approx .0175$. In the tenth year it will be

$$
C_{10}=\left[.02+.20\left(1.144^{10}-1.04^{10}\right)\right] / 1.144^{10} \approx .128 .
$$

Theorem 1 shows that, in expectation, the mimic's earnings in the final year will be at least $12.8 \%$ of a fund that has been compounding for ten years at the riskfree rate of $4 \%$.

To appreciate the magnitude of this effect, let us work out a simple example. Suppose that a fund starts with 100 million dollars. In the $t^{\text {th }}$ year, $t<10$, the mimic will earn at least $.0175(1.04)^{t} 100$ million dollars in expectation. In the tenth and final year he will earn at least $.128\left(1.04^{10}\right) 100=18.947$ million dollars in 
expectation. The probability that the mimic receives the final bonus, i.e., that the fund is not bankrupted before then, is at least $(1.1)^{-10}=.386$. In this case the amount of the bonus is $.20\left(1.144^{10}-1.04^{10}\right) 100=47.18$ million dollars. Thus the mimic has a $38.6 \%$ chance of earning a bonus equal to 47.18 million dollars, and a $61.4 \%$ of earning no bonus at all. (In the latter case, however, he may still collect the management fees.) To the extent that the mimic is impatient and/or risk averse, the expected utility of the final bonus is diminished, but by almost any measure it is very large in spite of the postponement. Moreover, the mimic can always diversify away the risk by running several mimicking funds in parallel that use independent options-based strategies.

\section{Manipulation-proof performance measures}

In this section we return to a question raised at the outset of this paper: given that there exist manipulation-proof performance measures (MPPM's), why are there not compensation mechanisms with the same property? The answer will become apparent once we examine the form of these measures. The unique class of MPPM's satisfying certain regularity conditions takes the form of an additively separable power function of the excess returns (Goetzmann et al., 2007). Specifically, let $\rho>0$ and consider the constant relative risk aversion (CRR) utility function $u(x)=(1-\rho)^{-1} x^{1-\rho}$. Suppose that a fund delivers the sequence of returns $M_{t}\left(1+r_{f t}\right), 1 \leq t \leq T$, that is, $M_{t}-1$ is the excess return in period $t$ relative to the risk-free rate. For any strictly increasing function $F$, an $M P P M$ can be defined as follows

$$
G(\vec{m})=F\left[(1-\rho)^{-1}(1 / T) \sum_{1 \leq t \leq T} m_{t}^{1-\rho}\right]
$$


Goetzmann et al. suggest the function $G(\vec{m})=(1-\rho)^{-1} \ln \left[(1 / T) \sum_{1 \leq t \leq T} m_{t}^{1-\rho}\right]$ with values of $\rho$ in the vicinity of $\rho=3$. A variant of this approach that is actually used by the rating firm Morningstar (2006) is

$$
\left.G^{*}(\vec{m})=\left[(1 / T) \sum_{1 \leq t \leq T} 1 / m_{t}^{2}\right)\right]^{-1 / 2}-1
$$

Suppose that a manager using strategy $\vec{M}$ is paid at the end of the $T^{\text {th }}$ period according to an increasing function of such a measure. To be specific, let us suppose he is paid in proportion to the Morningstar measure. If a manager delivers excess return $m_{t}=1+\alpha$ with certainty in each period, then $G^{*}(\vec{m})=\alpha$ and the manager is paid in proportion to $\alpha$. Suppose, however, that there is some variation in $m_{t}$. Since $T$ is finite, a manager who delivers positive $\alpha$ in expectation may nevertheless get unlucky and have negative payments at the end of the $T^{\text {th }}$ period (if some realizations $m_{t}$ are close to zero). In this case he has to pay the investors out of his own pocket. This might be acceptable if his total expected earnings are positive in expectation, but it turns out that in this case the mimics also have an incentive to enter, as we show in the following section. Moreover this holds not only for payments according to the Morningstar measure, but for any compensation mechanism: if the penalties are sufficient to screen out the mimics, then they screen out the skilled managers also. 


\section{Penalties}

Consider a compensation mechanism $\phi$ that sometimes takes on negative values, that is, $\phi_{t}(\vec{m}, \vec{x})<0$ for some values of $\vec{m}, \vec{x}$ and $t$. To avoid cumbersome notation we shall assume that the benchmark asset is risk-free and hence $x_{t}=1+r_{f t}$ for all $t$, that is, $\vec{x}=1+\vec{r}_{f}$. Without loss of generality we can assume

that a fund starts with initial value 1 . For each realization $\vec{m}$, let $\tilde{\phi}(\vec{m})$ denote the present value of the stream of fees generated by $\vec{m}$ discounted by the risk-free rate. Thus

$$
\tilde{\phi}(\vec{m})=\sum_{1 \leq t \leq T}\left[\left(m_{1} m_{2} \cdots m_{t}\right) \phi_{t}\left(\vec{m}, \overrightarrow{1}+\vec{r}_{f}\right)\right]
$$

Suppose that $\tilde{\phi}(\vec{m})<0$ for some realizations $\vec{m}$, and let

$$
-b=\min _{\vec{m}}\{\tilde{\phi}(\vec{m})\} .
$$

In order to cover future contingencies, at the start of the first period the manager must deposit a personal bond $b$ in an escrow account earning the risk-free rate until the final period $T$ is concluded. ${ }^{6}$

Now consider a hypothetical skilled manager who can deliver a stream of excess returns $\vec{m}^{*} \geq \overrightarrow{1}$ with certainty. The fact that he can do so is not known to the investors, so he must post a bond $b$ just like everyone else. However the

\footnotetext{
${ }^{6}$ If managers are paid in proportion to a measure of type (15), where $\rho>1$, the out-of-pocket penalties become unboundedly large as $m_{t}$ approaches zero, hence the bond would have to be infinite.
} 
manager knows that he can deliver $\vec{m}^{*}$, and the fees that go with it, with certainty. The present value of the fees plus the bond is $\tilde{\phi}\left(\vec{m}^{*}\right)+b$.

The skilled manager must compare this with the prospective payoff from investing $b$ in his own private fund and not taking any money from outside investors. The present value of this alternative to the skilled manager is $b \prod_{1 \leq t \leq T} m_{t}^{*}$. Therefore the skilled manager's incentive compatibility constraint is

$$
\tilde{\phi}\left(\vec{m}^{*}\right)+b>b \prod_{1 \leq t \leq T} m_{t}^{*} .
$$

Now consider an unskilled risk-neutral manager who mimics the sequence $\vec{m}^{*}$, as described in the proof of the Lemma. He must also post a bond $b$, and he may lose some (or all) of it if the fund goes bankrupt. It follows that the present expected value of the future stream of fees is at least $\tilde{\phi}(\vec{m}) / \prod_{1 \leq t \leq T} m_{t}^{*}$. By construction, the mimic cannot lose more than $b$ if the fund goes bankrupt, which occurs with probability at most $1-1 / \prod_{1 \leq t \leq T} m_{t}^{*}$. Therefore the present value of mimicking is positive if

$$
\left(\tilde{\phi}\left(\vec{m}^{*}\right)+b\right) / \prod_{1 \leq t \leq T} m_{t}^{*}>b .
$$

Rearranging we see that this holds whenever (19) holds. We have therefore established the following impossibility theorem. 
Theorem 2. There is no compensation mechanism, either with or without penalties, that separates skilled from unskilled managers on the basis of their track records. In particular, any compensation mechanism that deters unskilled risk-neutral mimics also deters managers of arbitrarily high skill levels.

\section{Attracting new money}

The preceding analysis shows that any compensation mechanism that rewards high-skill portfolio managers can be gamed by mimics without delivering any value-added to investors. To achieve this, however, the mimic takes a calculated risk in each period that his fund will suffer a total loss. A manager who is concerned about building a long-term reputation may not want to take such risks; indeed he may make more money in the long run if his returns are lower and he stays in business longer, because this strategy will attract a steady inflow of new money. However, while there is empirical evidence that past performance does affect the inflow of new money to some extent, the precise relationship between performance and flow is a matter of debate. ${ }^{7}$ Fortunately we can incorporate flow-performance relationships into our framework without committing ourselves to a specific model of how it works and the previous results remain essentially unchanged.

To see why, consider a benchmark asset generating returns series $\vec{X}$ and a strategy $\vec{M}$ for delivering excess returns relative to $\vec{X}$. Let $Z_{t}=Z_{t}\left(m_{1}, \ldots, m_{t-1} ; x_{1}, \ldots, x_{t-1}\right)$ be a random variable that describes how much net

7 See for example Gruber (1996), Massa, Goetzman, and Rouwenhorst (1999), Chevalier and Ellison (1997), Sirri and Tufano (1998), and Berk and Green (2004). 
new money flows into the fund at the start of period $t$ as a function of the returns in prior periods. We shall assume that $Z_{t}$ is multiplicative, that is, its realization $z_{t}$ is the proportion by which the fund grows (or shrinks) at the start of period $t$ compared to the amount that was in the fund at the end of period $t-1$. In particular, if a fund starts at size 1 , its total value at the start of period $t$ is

$$
Z_{t} \prod_{1 \leq s \leq t-1} M_{s} X_{s} Z_{s}
$$

Given any excess returns sequence $\vec{m} \geq \overrightarrow{1}$ over $T$ years, a mimic can reproduce it with probability $1 / \prod_{1 \leq t \leq T} m_{t}$ for all realizations of the benchmark returns. Since by hypothesis the flow of new money depends only on $\vec{m}$ and $\vec{x}$, the probability is at least $1 / \prod_{1 \leq t \leq T} m_{t}$ that the mimic will attract the same amount of new money into the fund as the skilled manager.

The question of what patterns of returns attract the largest inflow of new money is an open problem that we shall not attempt to address here. However, there is some evidence to suggest that investors are attracted to returns that are steady even though they are not spectacular. Consider, for example, a fund that grows at $1 \%$ per month year in and year out. (The recent Ponzi scheme of Bernard Madoff grew to some $\$ 50$ billion by offering returns of about this magnitude.) This can be generated by piggybacking on government bonds yielding $4 \%$, and the probability that the fund will go under in any given year is only $7.7 \%$ $\left(1-\left(1.04 / 1.01^{12}\right)=.077\right)$. In expectation, such a fund will stay in business and continue to attract new money for about 13 years. 


\section{Conclusion}

In this paper we have shown how mimicry can be used to game performance fees by portfolio managers. The framework allows us to estimate how much a mimic can earn under different incentive structures; it also shows that commonly advocated reforms of the incentive structure cannot be relied upon to screen out unskilled managers (and outright charlatans) who do not deliver excess returns to investors.

The analysis is non-standard from a game-theoretic standpoint, because we did not identify the set of players, their utility functions, or their strategy spaces. The reason is that we do not know how to specify any of these components with precision. To write down the players' utility functions, for example, we would need to know their discount factors and degrees of risk aversion, and we would also need to know how their track records generate inflows of new money. All of these elements are quite uncertain, and to try to model them explicitly would force us into making assumptions that we do not wish to make. The advantage of the mimicry argument is that one can draw inferences about the relationship between different players' earnings without knowing the details of their payoff functions or how their track records attract new money. The argument is that, if someone is producing returns that earn large fees in expectation, then someone else (with no skill) can mimic the first type and also earn large fees in expectation without knowing anything about how the first type is actually doing it. In this paper we shown how to apply this idea to financial markets. We conjecture that it may prove useful in other situations where there are many players, the game is complex, and the equilibria are difficult to pin down precisely. 


\section{References}

Ackermann, Carl, Richard MacEnally, and David Ravenscraft. 1999. “The performance of hedge funds: risk, return, and incentives." Journal of Finance 54: 833-874.

Berk, Jonathan B. and Richard C. Green. 2004. “Mutual fund flows and performance in rational markets." Journal of Political Economy 112: 1269-1295.

Carpenter, Jennifer. 2000. “Does option compensation increase managerial risk appetite?" Journal of Finance 55: 2311-2331.

Chevalier, Judith, and Glenn Ellison. 1997. "Risk taking by mutual funds as a response to incentives." Journal of Political Economy 105: 1167-1200.

Ferson, W., and A. Siegel. 2001. "The efficient use of conditioning information in portfolios," Journal of Finance 3: 967-982.

Gale, David. 1974. “A curious Nim-type game." The American Mathematical Monthly 81: 876-879.

Goetzmann, William, Jonathan E. Ingersoll, Matthew Spiegel, and Ivo Welch. 2007. “Portfolio performance manipulation and manipulation-proof performance measures." Review of Financial Studies 20: 1503-1546. 
Guasoni, Paolo, Gur Huberman, and Zhenyu Wang. 2007. “Performance maximization of actively managed funds." Working Paper, Boston University and Columbia Business School.

Gruber, Martin J. 1996. "Another puzzle: the growth in actively managed mutual funds." Journal of Finance 51: 783-810.

Hasanhodzic, Jasmina, and Andrew W. Lo. 2007. “Can hedge-fund returns be replicated?: the linear case." Journal of Investment Management 5: 5-45.

Hodder, James E. and Jens Carsten Jackwerth. 2007. "Incentive contracts and hedge fund management." Journal of Financial and Quantitative Analysis 42: 811826.

Hull, John C. 2009. Options, Futures and Other Derivatives, $7^{\text {th }}$ Edition. New York: Prentice-Hall.

Kat, Harry M., and Helder P. Palaro. 2005. “Who needs hedge funds: a copulabased approach to hedge fund return replication." Working Paper, Cass Business School, City University London.

Lhabitant, Francois-Serge. 2000. “Derivatives in portfolio management: why beating the market is easy," Derivatives Quarterly 6:39-45.

Lo, Andrew W. 2001. “Risk management for hedge funds: introduction and overview." Financial Analysts' Journal, November/December: 16-33. 
Massa, Massimo, William N. Goetzmann, and K. Geert Rouwenhorst. 1999.

"Behavioral factors in mutual fund inflows." Yale ICF Working Paper No. 00-14.

Morningstar, 2006, "The Morningstar rating methodology,"

http://corporate.morningstar.com/US/documents/MethodologyDocuments/Meth odologyPapers/MorningstarFundRating_Methdology.pdf

Sirri, Erik R. and Peter Tufano. 1998. "Costly search and mutual fund inflows." Journal of Finance 53: 1589-1622.

Starks, Laura T. 1987. "Performance incentive fees: an agency theoretic approach." Financial and Quantitative Analysis 22: 17-32. 